\title{
Respiratory Health Upshots due to Contaminated Living Environment: A Cross-Sectional Study of the Industrial Belt of Kanpur City, India
}

https://doi.org/10.21272/sec.4(1).17-27.2020

Gyan Chandra Kashyap, ORCID: https://orcid.org/0000-0003-0404-437X

PhD, Assistant Professor, Indian Institute of Health Management Research (IIHMR Bangalore), India

Parul Puri, ORCID: https://orcid.org/0000-0001-6272-837X

MPhil, Doctoral Fellow, International Institute for Population Sciences, India

Shri Kant Singh, ORCID: https://orcid.org/0000-0003-0824-9073

PhD, Professor, Department of Mathematical Demography, Faculty of Statistics, International Institute for Population Sciences, India

\begin{abstract}
In recent decades, air pollution has become a real threat to the lives and health of populations around the world. Today, about $92 \%$ of the world's population lives in areas with low air quality standards. In India, in particular, air pollution is one of the main causes of respiratory and allergic diseases, asthma, chronic obstructive pulmonary disease, pneumonia and even tuberculosis. The purpose of this study is to analyze the extent of the spread of respiratory diseases in people living near the leather manufacturing industry in Jamau, Kanpur, India. The source of information is a cross-sectoral survey of male workers from the Jamau area, for which a three-stage sampling model is used. The study area selected areas of Bujiat, Motinagar and Asharfabad because of the high concentration of the population employed in leather processing plants. During the study, the authors used one- and two-dimensional statistics. The study showed that there are no major benefits of civilization in the study areas: housing, water, hygiene and sanitation, waste treatment, etc. In the last 12 months, it was found that $11 \%$ of the population in the aforementioned territory experienced symptoms such as wheezing or wheezing at any time of the day, ie permanently, and another $9 \%$ of the population were waking up from chest tightness in the previous 12 months. During the survey period, $10 \%$ of the respondents had coughing sputum at least three months before the day or night. The rapid spread of various respiratory diseases may be associated with higher levels of air pollution. The article presents the recommendations of the authors on adherence to the principles of fair industrial activity within the framework of corporate social responsibility and promotion of sustainable development of territories.
\end{abstract}

Keywords: living environment, morbidity, respiratory health, workers.

JEL Classification: I12, I14, J21, J81, L10, Q5, Q53.

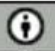

This work is licensed under a Creative Commons Attribution 4.0 International License.

Cite as: Gyan Chandra Kashyap, Parul Puri, Shri Kant Singh (2020). Respiratory Health Upshots due to Contaminated Living Environment: A Cross-Sectional Study of the Industrial Belt of Kanpur City, India. SocioEconomic Challenges, 4(1), 17-27. https://doi.org/10.21272/sec.4(1). 17-27.2020.

(C) The Authors, 2020. This article is published with open access at Sumy State University. 


\section{Introduction}

The Sustainable Development Goals (SDG) were aimed at edifying a more inclusive, sustainable, and resilient future by ensuring complete socio-economic and environmental indemnity for the population [1]. Three SDGs that are specifically dedicated to the ecosystem, namely, climate (Goal-13), oceans (Goal-14), and land (Goal15). However, SDGs have been criticized for resting no direct prominence on 'Air Pollution' [2]. In the past decades, air pollution has emerged as a severe public health disaster worldwide. Estimates suggest that 92 percent of the world's population still lives in areas with poor air quality standards [3]. Globally, around 6.5 million deaths occurred due to air-pollution related diseases. In India, Evidence suggests that air pollution contributes to the global burden of respiratory and allergic diseases together with asthma, chronic obstructive pulmonary disease, pneumonia, and possibly tuberculosis, although associations between air pollution and respiratory illnesses are complex[4,5]. A report published by the Forum of International Respiratory Societies identifies five conditions, namely asthma, chronic obstructive pulmonary disease, acute respiratory infections, tuberculosis, and lung cancer that primarily contribute to the global burden of respiratory diseases [6]. Most commonly, exposure to air pollution has many substantial adverse effects on human health. Annually, seven million deaths were attributed to the joint effects of household and ambient air pollution [7]. Air pollution can induce the acute exacerbation of COPD and the onset of asthma, increase respiratory morbidity, and mortality [7].

Many studies reveal that environmental health risks are significantly higher for the countries belonging to low-and-middle economies, where lack of investment in modern technology, and weak environmental legislation combine to cause high pollution levels. Association between environmental pollution and health outcome are, however, complex and often poorly characterized. Most importantly, long latency time, effects of cumulative exposures, and multiple exposures to different pollutants that might act synergistically all create difficulties in unraveling associations between environmental pollution and health [8].

In a population survey in India, the use of traditional solid fuels such as wood, coal, etc. were found to have adverse effects on the pulmonary functions of an exposed individual. WHO estimated that household indoor air pollution would cause a cumulative total of 9.8 million premature deaths by the year 2030 [5]. Household air pollution is a prominent cause of disability-adjusted life years (DALYs) in Southeast Asia and the third leading cause, globally [9]. Around half of the world, the population lives in urban areas and are exposed to progressively higher levels of air pollutants [10].

Kanpur city secures the worst city appellation, with PM 2.5 concentrations of 173 micrograms per cubic meter $^{3}$. It is the largest city in the Uttar Pradesh state of India. Kanpur has a spread of $260 \mathrm{~km}^{2}$, with a population of 25.51 lakh, which is expected to double by 2030 [11]. The splendor of the leather industries is dated even before the advent of the British Raj took place in India. Although the establishment of an industrial belt in Kanpur brought economic benefits for the tannery owners, however, there is a devastating impact on the living environment of the area, especially for the households that do not belong to economically well-off groups. The housing localities in Kanpur are blemished by unclean living conditions and lack of civic amenities. The population of about five lakhs lives in slums with at most a zilch in the appellation of hygiene and sanitation. Estimates from the socio-economic survey conducted by the Kanpur Development Authority (KDA) suggest that about 67 percent of the households in Kanpur live in a single room or portion. Besides this, the contaminating nature of these leather tanneries can be witnessed from the stinking odors that envelopes the periphery of this industrial belt.

Jajmau, a suburb on the eastern part of the city of Kanpur Nagar, is situated on the banks of the river Ganges. It is an industrial area and is believed to be the oldest inhabited place in the region. It is the home to some of the biggest leather tanneries in Northern India. Leather industries are the primary source of menacing pollution in the city, especially in this area. Estimates suggest that these tanneries pump out about 30 crore liters of polluted water into the river Ganges, which flows adjacent to the city. Additionally, about 400 tons of solid waste is generated every year. The elevated rates of pollution have, in turn, contaminates the groundwater sources in the city [12].

There is evidence of the relationship between the living environment and the health of the population worldwide. Even at a glance, there is a preponderance of air pollution over other environmental risk factors in the city. Moreover, studies in the past suggest that there is a total of 74.7 million Disability Adjusted Life Years (DALYs) lost due to contaminants that cause air pollution [3]. These contaminants, in turn, increase the burden of various diseases in the population. There are a variety of disorders such as asthma, chronic 
bronchitis, tuberculosis, lung cancer, cardiovascular diseases, cognitive disorders, etc., which are caused due to contaminated air. Additionally, there is evidence which supports that effect of housing condition on the health of its inmates [1].

Altogether, it would be right to say that respiratory disorders or symptoms may be attributed to a variety of factors like housing facilities, sanitation and hygiene practices, kind of energy used in the household, etc. Air pollution has many adverse health effects on the general population. Individuals of the Jajmau area spend an enormous time of their lives in a contaminated environment (working as well as their living environment); thus, the adverse environment might influence their health status. The present study aims to explore how the environment affects the health of the people of the Jajmau area of Kanpur city, which is a hub of leather tanneries. Therefore, the study was intended to estimate the prevalence and pattern of respiratory health problems among people living in adjoining areas of the leather industry of the Jajmau area in Kanpur City, India.

\section{Materials and methods}

As mentioned before, the study is conducted in Jajmau area of Kanpur, Uttar Pradesh, in India, which is a significant leather-processing region in the state. As per Census, 2011, the city of Kanpur has a population of $2,767,031$. The city had a decadal growth rate of 10 percent during (2001-2011). Kanpur holds 9th rank among the top ten industrial cities in India, with a total GDP (PPP) of 22 billion USD. Kanpur has conventionally been an industrial city and a major economic center in Uttar Pradesh. At present, the city has 402 registered leather tanneries which are concentrated in the eastern part of the city with an estimated 20,000 tannery workers. The tanning industry is considered to be immensely polluting with environmental impact on water, terrestrial, and atmospheric systems.

The data is acquired from a cross-sectional household survey of the male inhabitants in the area. The study was conducted during the period of January-June 2015 in the Jajmau. The study respondents are male tannery workers aged 16 years or above. Out of 600 men selected from the households in the Jajmau, 573 were interviewed with a response rate of 95 percent. Jajmau is divided into several small wards: Tadbagiya, Kailash Nagar, J. K. colony, Asharfabad, Motinagar, Chabeelepurwa, and Budhiyaghat Teela. Most of the inhabitants are engaged in labor work in the leather industry. More than 20,000 people were working in the leather industry, and among them, a sizeable proportion of tannery workers were living in the same area.

Sampling Design. The three-stage sampling design was adopted for the survey. The first stage comprised of selecting seven localities in the Jajmau area, namely, Tadbagiya, Kailash Nagar, J.K. colony, Asharfabad, Motinagar, Chabeelepurwa, and Budhiyaghat. These wards were selected based on the higher concentration of leather tannery worker's population in these areas as reported by various stakeholders in the city. In the second stage, the seven localities were arranged in increasing order of estimated number of HHs of leather tannery workers. With the help of the probability proportional to size (PPS) sampling technique, three out of the seven localities, namely, Budhiyaghat, Tadbagiya, and Asharfabad, were chosen. The next stage was to select households. For this, a comprehensive household listing and mapping were carried out in each of the three localities. Once the updated and comprehensive sampling frames were developed, the households were selected by using circular systematic random sampling method. In the third and the last stage, the households that presented with more than one eligible respondent, the target respondent was selected using the KISH table. Two hundred households were selected in each of the three selected areas.

Thus, a total of $600 \mathrm{HHs}$ were chosen for the interview. The research team could successfully interview a total of $573 \mathrm{HHs}$ for this study. The team undertook extensive field visits before data collection and designed the interview schedule. The questionnaire was translated into local language (Hindi), pre-tested, and face-to-face interviews were conducted. Auxiliary information for the study was collected from World Health Organization [3] website for the air pollution data Univariate and bivariate analyses were used to estimate the prevalence and determine correlates of respiratory health problems.

\section{Results}

The air pollution level is increasing all over the world, with developing countries being worse affected. At present, India stands on the most critical cut-off point. A most recent estimate of WHO's World Global Ambient Air Quality Database (2016) exhibits that 11 out of the 12 most polluted cities are in India. The PM 
2.5 values are the highest in Kanpur (PM2.5=173), followed by Faridabad (PM2.5=172), Varanasi (PM2.5=151), and the lowest value of PM2.5 is 98 for the Jodhpur.

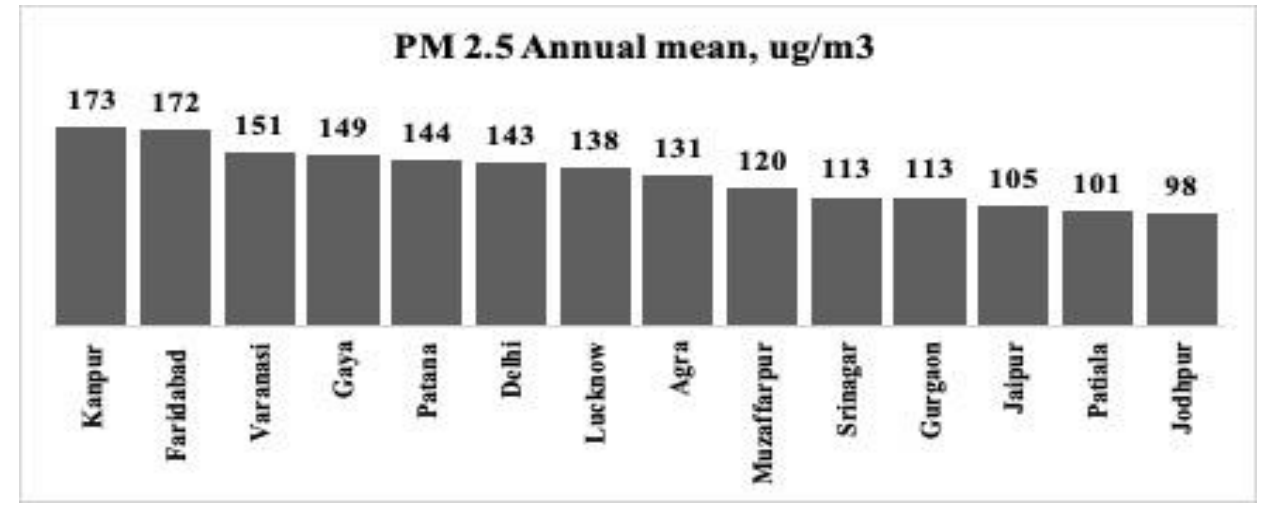

Figure 1. Level of Particulate Matter (PM) 2.5 of selected cities in India, 2016

Source: World Health Organization (WHO) global air pollution database https://www.who.int/airpollution/data/cities/en/.

The sample size (total number of households and number of interviewed households) is presented in Table 1. The survey was conducted out in three areas, namely; Budhiyaghat, Tadbagiya, and Ashrfabad. A slightly over 600 households were in Budhiyaghat, 562 in Tadbagiya and 360 in Ashrfabad. The study has interviewed 573 individuals, from 200 households from Budhiyaghat, 185 from Tadbagiya and 188 from Ashrfabad from the Jajmau area of Kanpur Nagar, Uttar Pradesh, India. The socio-economic profile of the respondents is presented in Table 2.

Table 1. Population and sample size of the study area

\begin{tabular}{|l|c|c|}
\hline \multirow{2}{*}{ Areas } & \multicolumn{2}{|c|}{ Number of Households (HH) } \\
\cline { 2 - 3 } & Number of HHs & Number of HHs Interviewed \\
\hline Budhiyaghat & 600 & 200 \\
\hline Tadbagiya & 562 & 185 \\
\hline Ashrfabad & 360 & 188 \\
\hline Total & & $\mathbf{5 7 3}$ \\
\hline
\end{tabular}

Source: Estimates are based on author's primary data.

Table 2. Socio-economic profile of the respondents of Jajmau area of Kanpur City, India

\begin{tabular}{|l|c|c|}
\hline \multicolumn{1}{|c|}{ Characteristics } & Number (N) & Percentage (\%) \\
\hline Education & & 64.1 \\
\hline No Education & 366 & 11.21 \\
\hline Up to Primary & 64 & 15.94 \\
\hline Middle School & 50 & 37.7 \\
\hline High School and Above & 91 & 62.3 \\
\hline Religion & 216 & 50.44 \\
\hline Hindu & 357 & 26.35 \\
\hline Muslim & & 23.21 \\
\hline Caste & 289 & 33.39 \\
\hline Scheduled Castes & 151 & 33.74 \\
\hline Other Backward Class & 133 & 32.87 \\
\hline Others & & \\
\hline Standard of Living Index & 191 & 49.04 \\
\hline Poor & 193 & 50.96 \\
\hline Middle & 188 & \\
\hline Rich & & \\
\hline Employment Type & 281 & 9.58 \\
\hline Tannery Worker & 292 & \\
\hline Non- Tannery Worker & & \\
\hline Household in Poverty (BPL) & 32 & \\
\hline Yes & 541 & \\
\hline No & & \\
\hline
\end{tabular}

Source: Estimates are based on author's primary data. 
Table 3 shows the household characteristics that include the toilet facilities, water sources, hygiene and sanitation facilities, and the drainage system in the study area. From the results; half of the respondents lived in a semi-pucca house; little less than one-fifth of the respondents (19\%) lived in kaccha houses, and the rest (30\%) lived in pucca houses. Only 15 percent of the households had a separate kitchen for cooking. A substantial proportion of the households (40\%) were still using solid fuel for cooking in the survey community. Around one-third of the respondents (34\%) reported that they were accessing drinking water from the public tap/standpipe. A substantial proportion of the respondents informed that they usually wash their hands before a meal, after a meal, and after defecation. The majority of the households reported that there is no arrangement of solid waste discharge; even garbage pits were not available in the area. Most notably, fifty-four percent of the study population was using open space for defecation. Furthermore, 18 percent of households were using toilet facilities on a sharing basis with those who had a toilet facility.

Table 3. Housing and energy, water sources, hygiene and sanitation practices, waste discharge and toilet facilities in Jajmau area of Kanpur city, India

\begin{tabular}{|c|c|c|}
\hline Characteristics & Number $(\mathrm{N})$ & Percentage $(\%)$ \\
\hline \multicolumn{3}{|l|}{ Housing and Energy } \\
\hline \multicolumn{3}{|l|}{ Type of House } \\
\hline Kachha & 109 & 19.0 \\
\hline Semi-Pucca & 295 & 51.5 \\
\hline Pucca & 169 & 29.5 \\
\hline \multicolumn{3}{|l|}{ Number of rooms used for sleeping } \\
\hline One & 343 & 59.9 \\
\hline Two or more & 230 & 40.1 \\
\hline \multicolumn{3}{|l|}{ Separate Kitchen } \\
\hline Yes & 87 & 15.2 \\
\hline No & 486 & 84.8 \\
\hline \multicolumn{3}{|l|}{ Type of Fuel Used } \\
\hline LPG/Natural Gas & 276 & 48.2 \\
\hline Kerosene & 62 & 10.8 \\
\hline Solid Fuel & 235 & 41.0 \\
\hline \multicolumn{3}{|l|}{ Water } \\
\hline \multicolumn{3}{|l|}{ Main Source of drinking water } \\
\hline Piped to dwelling & 53 & 9.3 \\
\hline Piped to yard/plot & 238 & 41.5 \\
\hline Public Tap/Standpipe & 196 & 34.2 \\
\hline Tube well/ Borehole & 86 & 15.0 \\
\hline \multicolumn{3}{|l|}{ Water Potability } \\
\hline Yes & 6 & 1.1 \\
\hline No & 567 & 98.9 \\
\hline \multicolumn{3}{|l|}{ Hygiene and Sanitation } \\
\hline \multicolumn{3}{|l|}{ Hand wash before meal } \\
\hline Often & 345 & 60.2 \\
\hline Sometimes & 224 & 39.1 \\
\hline Never & 4 & 0.7 \\
\hline \multicolumn{3}{|l|}{ Hand wash after meal } \\
\hline Often & 229 & 40.0 \\
\hline Sometimes & 314 & 55.0 \\
\hline Never & 30 & 5.0 \\
\hline \multicolumn{3}{|l|}{ Hand wash after defecation } \\
\hline Often & 530 & 92.5 \\
\hline Sometimes & 38 & 6.6 \\
\hline Never & 5 & 0.9 \\
\hline \multicolumn{3}{|l|}{ Waste Discharge } \\
\hline \multicolumn{3}{|l|}{ Arrangement of Solid Waste Discharge } \\
\hline Yes & 183 & 31.9 \\
\hline No & 390 & 68.1 \\
\hline \multicolumn{3}{|l|}{ Presence of Garbage Pit } \\
\hline Yes & 86 & 15.0 \\
\hline No & 487 & 85.0 \\
\hline \multicolumn{3}{|l|}{ Toilet } \\
\hline Type of Toilet Facility & & \\
\hline
\end{tabular}


Table 3 (cont.). Housing and energy, water sources, hygiene and sanitation practices, waste discharge and toilet facilities in Jajmau area of Kanpur city, India

\begin{tabular}{|c|c|c|}
\hline Characteristics & Number $(\mathrm{N})$ & Percentage $(\%)$ \\
\hline Flush to piped sewer system & 110 & 19.2 \\
\hline Flush to septic tank & 154 & 26.9 \\
\hline No Facilities/ Open Space & 309 & 53.9 \\
\hline \multicolumn{3}{|l|}{ Shared Toilet } \\
\hline Yes & 103 & 18.0 \\
\hline No & 469 & 82.0 \\
\hline
\end{tabular}

Source: Estimates are based on author's primary data.

The prevalence of self-reported symptoms of Asthma and Chronic Bronchitis among study population in the Jajmau area of Kanpur Nagar is presented in Table 4. Results show that the symptoms of Asthma and Chronic Bronchitis were higher among the study population than the previous city-level estimates. The prevalence of the symptoms such as wheezing or whistling in the chest at any time in the last 12 months is found to be $11 \%$. Nine percent reported waking up with a feeling of tightness in the chest at any time in the last 12 months. A cough up phlegm most days or nights for at least three months in previous year (10\%), usually bring up phlegm from the chest first thing in the morning (18\%), brought up phlegm from the chest like this most mornings for at least three months in previous year $(9 \%)$, usually have a cough (16\%) were also reported by the respondents. Also, the prevalence of those having any nasal allergies $(9.3 \%)$ and usually experience chest contestation $(14 \%)$ was higher among the survey population in the Jajmau area of Kanpur Nagar.

Table 4. Prevalence of self-reported symptoms of Asthma and Chronic Bronchitis among study population in Jajmau area of Kanpur city, India, 2015

\begin{tabular}{|c|c|c|}
\hline $\begin{array}{c}\text { Self-reported Symptoms } \\
\end{array}$ & Number $(\mathrm{N})$ & Percent $(\%)$ \\
\hline Wheezing or whistling in your chest at any time in the last 12 months & 60 & 10.5 \\
\hline All breathless when the wheezing noise was present & 41 & 7.2 \\
\hline Wheezing or whistling when you did not have a cold & 30 & 5.2 \\
\hline Woken up with a feeling of tightness in your chest at any time in the last 12 months & 50 & 8.7 \\
\hline Woken by an attack of shortness of breath at any time in the last 12 months & 29 & 5.1 \\
\hline A cough most days and nights for at least 3 months in the previous year & 11 & 1.9 \\
\hline A cough up phlegm most days or nights for at least 3 months in previous year & 57 & 10.0 \\
\hline Usually, have a cough first thing in the morning & 50 & 8.7 \\
\hline Usually bring up phlegm from your chest first thing in the morning & 100 & 17.5 \\
\hline Brought up phlegm from your chest like this most mornings for at least 3 months in previous year & 52 & 9.1 \\
\hline Had a flu-like illness with aches and pains, fever, chills, and night sweats in last 12 months & 219 & 38.2 \\
\hline Usually have a cough & 93 & 16.2 \\
\hline Have any nasal allergies & 53 & 9.3 \\
\hline Usually experience through irritation & 52 & 9.1 \\
\hline Usually experience chest contestation & 79 & 13.8 \\
\hline
\end{tabular}

Source: Estimates are based on author's primary data

Prevalence of self-reported symptoms of Tuberculosis among the study population is presented in Table 5. The prevalence of symptoms of tuberculosis was considerably higher than the previous estimates. Specifically, the prevalence of symptoms such as a cough usually with mucus (34\%), weight loss (27\%), breathing difficulty (26\%), chest pain (28\%), wheezing $(11 \%)$ and coughing up blood $(4 \%)$ was higher than in the city or the state.

Table 5. Prevalence of self-reported symptoms of Tuberculosis among study population in Jajmau area of Kanpur City, India, 2015

\begin{tabular}{|c|c|c|}
\hline Self-reported symptoms & Number $(\mathrm{N})$ & Percentage $(\%)$ \\
\hline Cough (usually with mucus) & 193 & 33.7 \\
\hline Coughing up blood & 21 & 3.7 \\
\hline Excessive sweating, especially at night & 149 & 26.0 \\
\hline Fatigue & 326 & 56.9 \\
\hline Fever & 239 & 41.7 \\
\hline Weight loss & 153 & 26.7 \\
\hline Breathing difficulty & 148 & 25.8 \\
\hline Chest pain & 160 & 27.9 \\
\hline Wheezing & 65 & 11.3 \\
\hline
\end{tabular}

Source: Estimates are based on author's primary data. 
The study also explores the determinants of morbidity in the Jajmau area. Table 6 showed the association between selected household characteristics and reported health issues amongst the selected sample of men. The findings reveal that variables such as the type of house, number of rooms for sleeping, separate kitchen, type of fuel used, main source of drinking water, washing hands after meal were found to be significantly associated with reporting health issues. The reported health problems were higher amongst men who live in kachha house (37.76\%), have one room for sleeping (31.21\%), do not have a separate kitchen $(29.00 \%)$, and use solid fuel for cooking (34.67\%).

Table 6. Association between selected household characteristics and reported respiratory health issues by men in Jajmau area of Kanpur City, India, 2015

\begin{tabular}{|c|c|}
\hline Household Characteristics & Respiratory Health Issue \\
\hline \multicolumn{2}{|l|}{ Type of House } \\
\hline Kachha & 17.76 \\
\hline Semi-Pucca & 34.75 \\
\hline Pucca & 22.42 \\
\hline \multicolumn{2}{|c|}{$\chi^{2}=14.54, p$-value $=0.001$} \\
\hline \multicolumn{2}{|c|}{ Number of rooms used for sleeping } \\
\hline One & 31.21 \\
\hline Two or more & 22.87 \\
\hline \multicolumn{2}{|c|}{$\chi 2=4.61, p$-value $=0.032$} \\
\hline \multicolumn{2}{|l|}{ Separate Kitchen } \\
\hline Yes & 21.18 \\
\hline No & 29.00 \\
\hline \multicolumn{2}{|c|}{$\chi 2=2.19, p$-value $=0.043$} \\
\hline \multicolumn{2}{|l|}{ Type of Fuel Used } \\
\hline LPG/Natural Gas & 23.62 \\
\hline Kerosene & 30.69 \\
\hline Solid Fuel & 34.67 \\
\hline \multicolumn{2}{|c|}{$\chi 2=9.11, \mathrm{p}$-value $=0.011$} \\
\hline \multicolumn{2}{|l|}{ Water } \\
\hline \multicolumn{2}{|c|}{ Main Source of drinking water } \\
\hline Piped to dwelling & 23.08 \\
\hline Piped to yard/plot & 34.47 \\
\hline Public Tap/Standpipe & 22.83 \\
\hline Tube well/Borehole & 23.17 \\
\hline \multicolumn{2}{|c|}{$\chi 2=8.92, \mathrm{p}$-value $=0.030$} \\
\hline \multicolumn{2}{|c|}{ Waste Discharge } \\
\hline \multicolumn{2}{|c|}{ Arrangement of Solid Waste Discharge } \\
\hline Yes & 33.33 \\
\hline No & 27.74 \\
\hline \multicolumn{2}{|c|}{$\chi 2=0.09, p$-value $=0.761$} \\
\hline \multicolumn{2}{|l|}{ Shared Toilet } \\
\hline Yes & 21.57 \\
\hline No & 29.05 \\
\hline \multicolumn{2}{|c|}{$\chi 2=2.32, p-$ value $=0.127$} \\
\hline
\end{tabular}

Source: Estimates are based on author's primary data.

\section{Discussion}

According to the recent air quality report from WHO's World Global Ambient Quality Database, 11 out of 12 cities with the high-level adulterated air are located in India. Kanpur tops the chart, with most adulterated 
air in India ${ }^{13}$. Existing literature provides evidence which proposes the preponderance of air-pollution-related deaths in the Low-and-middle-income Countries (LMICs). These studies highlight accelerated economic growth and unplanned industrialization as the primary reason for the increased level of air pollution and the related burden of diseases. Moreover, as already discussed in the background of the paper, it is quite clear that Kanpur has historically been and still is an industrial area with leather tanneries as the major industry in the city.

A total number of 573 respondents were interviewed in the study who lived in the vicinity of the tanneries. The study explored the characteristics which were linked with the living environment of the area. Factors such as housing and energy, water, hygiene and sanitation, toilet, and waste discharge were included in the study for apprehending the living environment.

This study presents an overall view of environmental living conditions and symptoms of respiratory disorders. The findings report that a high percentage of the study sample lived in the adulterated environment, additionally, in the absence of basic amenities like toilet, waste disposal facilities, etc. Major issues relating to living environment were that most of the households were either kuchha or semi-pucca, with most of them utilizing single room for sleeping, most do not have a separate kitchen in the house and used kerosene or other solid fuel like coal, charcoal, wood, etc. for the cooking food and energy. Only 2 percent had access to clean drinking water. Open defecation is a serious issue in the wake of the government's Swachchh Bharat Abhiyan, it has to be given a top priority.

Furthermore, a large share of the population had no facility to dispose-off solid waste. The primary factors responsible for this lousy living environment could be a poor economic status and low literacy rates. Also, as clear from the findings that only a small proportion of individuals had Below Poverty Line (BPL) cards, thus they have no accessibility subsidized facilities under the Public Distribution Scheme of India and other schemes designed for the poor. So, purchasing food products would be a priority, whereas, maintaining a better living standard, comes last. Moreover, because of the low level of education, the respondents lack the general awareness and cleanliness etiquettes required for health and well-being. Existing studies which focused on people living in the catchment areas of various industrial and occupational set-up have demonstrated a poor quality of life and health ${ }^{8}$.

Additionally, these workers lack essential household amenities like a pucca house, separate toilet, and kitchen, clean drinking water, and sanitation measures. These workers generally belong to the economically poor background with a low level of awareness concerning health and sanitation. They are not only a victim of pollution; they also contribute to it by utilizing unclean sources of energy for cooking and for keeping the households warm. These unclean sources of fuel include coal, kerosene, wood, charcoal, etc., which produces smoke. This smoke, in turn, elevates the rate of what is called Indoor Air Pollution (IAP). Both small- and large-scale studies, based on the above context, propose that, in general, there is an adverse effect of IAP on the health of its household members. Thus, the present study suggests a double burden of air pollution which affects the health, first, Indoor Air Pollution, and second, Outdoor Air Pollution, which is mostly contributed by industries in the periphery.

Besides, the prevalence of self-reported symptoms of Asthma and Chronic Bronchitis among the study population in the Jajmau area of Kanpur Nagar was also observed. Existing literature suggests that globally, air pollution as a major cause of deteriorating health of the population, with an estimated 2.9 million deaths per year ${ }^{3}$. Studies conducted in the past have reported similar results, which depict that the air pollution caused by industries has a deteriorating effect on the respiratory health of the population living in adjacent areas. The industries release obnoxious gases and particulate components like particulate matter (PM), nitrogen dioxide $\left(\mathrm{NO}_{2}\right)$, sulphur dioxide $\left(\mathrm{SO}_{2}\right)$, ethylene, formaldehyde, toluene, and benzene ${ }^{14,15,16,17}$.

A study appraises the human health due to the concentrations of $\mathrm{NO}_{2}, \mathrm{SO}_{2}$, and PM10 found that the number of cases increased almost twice (13.4 to 27.5\%) between 2002 and $2014^{18}$. A study conducted in China reveals that the COPD prevalence was significantly associated with elevated PM concentration levels ${ }^{19}$.

Studies reflect the effect of these exposures on the respiratory symptoms like wheezing, coughing, breathlessness, shortness of breath, tightness in chest, phlegm, fever, chills, etc ${ }^{20}$. Moreover, air pollution is also the cause of a variety of another disease which comes under the category of cardio-respiratory health outcomes. Study findings highlight that contamination of air quality threatens everyone on the planet, but 
mostly it is the economically marginalized sections of society which bear the disproportionate burden ${ }^{21}$ The existing literature suggests that, the level has been observed at the critical level, while a study conducted in Kolkata reveals that only $39.3 \%$ of the study participants have felt that outdoor (air) pollution has affected their health. Earlier studies identified the sources of pollution were vehicular emission (51.4\%), followed by industrial sources $(24.5 \%)$ and dust particles $(21.1 \%)^{22}$.

A study showed the association between the prevalence of chronic bronchitis and indoor smoke pollution, and the prevalence of chronic bronchitis increases with the exposure time ${ }^{23}$. People from the polluted area reported the increment in chronic bronchitis and emphysema, breathlessness, and mucus hypersecretion ${ }^{15}$. Another study reviewed the different epidemiological studies to understand the respiratory effects of indoor air pollutants quantitatively in industrialized countries. Outcomes support the association of adulterated environment on asthma, chronic bronchitis, and chronic obstructive pulmonary disease (COPD) in indoor settings with poor air quality ${ }^{16}$. This study supports earlier findings [24,25,26,27].

The present study depicts the living conditions and symptomatic respiratory conditions of the respondents from the Jajmau, an industrial belt from Kanpur. The study suggests that such areas of excessively high morbidity rates must be identified and the vital sources of pollution in the areas must be checked to protect the health of the people. The study recommends more research dealing with the effect of the pollutants separately on the health of the population. The use of a cross-sectional survey may have under-rated the actual prevalence of morbidity prevalence. Further, as the present study is based on self-reported data, some subjectivity in responses might have occurred.

\section{Conclusions}

Environmental (indoor and outdoor) air pollution from different sources is a major preventable cause of increased incidence and exacerbation of the respiratory disease. This study raises concerns regarding various respiratory disorders that are prevailing in the area due to higher levels of air pollution. However, many of these diseases are avoidable. Much of the disease can be mitigated through improving the household environmental conditions, relieving overcrowding, and educating people regarding the importance of hygiene and sanitation. Early health checkups at the time of symptoms first seen or felt can reduce respiratory health problems. Another crucial point is to observe the industry activities under the Corporate Social Responsibility (CSR) and spread awareness concerning the hazardous work \& living environment. In that case, the respondent may take preventive measures, and that can minimize the respiratory health problems in the study area.

\section{Contributors}

\section{Author contributions}

Conceptualization: GCK, PP, SKS; Methodology: GCK, SKS; results: GCK, PP; discussion/conclusion: GCK, PP, SKS.

\section{Funding}

This research received no specific grant from any funding agency, commercial entity or not-for-profit organization.

\section{Competing Interest}

The authors have no conflicts of interest to declare.

\section{Ethical Consent}

This work being based on the Ph.D. work of the first author, we have received the ethical clearance from the Student Research Ethics Committee of International Institute for Population Sciences Mumbai, India. We have also received a consent to participate from each of the respondents before starting the interview.

\section{References}

1. Singh, S.K., Kashyap, G.C. and Puri, P. (2018). Potential effect of household environment on prevalence of tuberculosis in India: evidence from the recent round of a cross-sectional survey. BMC pulmonary medicine, 18(1), p. 66. DOI: https://bmcpulmmed.biomedcentral.com/articles/10.1186/s12890-018-0627-3. 
2. Landrigan, P.J., Fuller, R., Acosta, N.J., Adeyi, O., Arnold, R., Baldé, A.B., Bertollini, R., Bose-O'Reilly, S., Boufford, J.I., Breysse, P.N. and Chiles, T., 2018. The Lancet Commission on pollution and health. The Lancet, 391(10119), 462-512. DOI: https://doi.org/10.1016/S0140-6736(17)32345-0

3. World Health Organization (2016). Ambient air pollution: A global assessment of exposure and burden of disease. https://www.who.int/phe/publications/air-pollution-global-assessment/en/

4. Kampa, M. and Castanas, E. (2008). Human health effects of air pollution. Environmental pollution, 151(2), pp.362-367. DOI: https://doi.org/10.1016/j.envpol.2007.06.012

5. World Health Organization (2014). Global surveillance, prevention and control of chronic respiratory diseases: a comprehensive approach. Geneva, Switzerland: World Health Organization; 2007. https://www.who.int/gard/publications/GARD_Manual/en/

6. Ferkol, T. and Schraufnagel, D. (2014). The global burden of respiratory disease. Annals of the American Thoracic Society, 11(3), pp.404-406. DOI: doi: 10.1513/AnnalsATS.201311-405PS.

7. Jiang, X.Q., Mei, X.D. and Feng, D. (2016). Air pollution and chronic airway diseases: what should people know and do? Journal of thoracic disease, 8(1), p.E31. 10.3978/j.issn.2072-1439.2015.11.50

8. Briggs, D. (2003). Environmental pollution and the global burden of disease. British medical bulletin, 68(1), 1-24. DOI: https://doi.org/10.1093/bmb/ldg019

9. Apte, K. and Salvi, S. 2016. Household air pollution and its effects on health. F1000Research, 5. https://f1000research.com/articles/5-2593

10. Arbex, M.A., Santos, U.D.P., Martins, L.C., Saldiva, P.H.N., Pereira, L.A.A. and Braga, A.L.F. (2012). Air pollution and the respiratory system. Jornal brasileiro de pneumologia, 38(5), 643-655. DOI: http://dx.doi.org/10.1590/S1806-37132012000500015

11. Environmental Issues Related to Leather Industry. (n.d.) (133), 133-158. Retrieved from http://shodhganga.inflibnet.ac.in/bitstream/10603/175866/14/14 chapter 6.pdf

12. Leather Industry in Kanpur: Rise and Growth during Colonial Period, 1850. https://shodhganga.inflibnet.ac.in/bitstream/10603/175866/11/11_chapter\%203.pdf

13. Equation THE, Simple, I. S. (n.d.). The equation is simple. https://www.cecindia.org/libpdf/1437550410LeatherIndustryinIndia.pdf

14. Bergstra, A.D., Brunekreef, B. and Burdorf, A. (2018). The effect of industry-related air pollution on lung function and respiratory symptoms in school children. Environmental Health, 17(1), p.30. DOI: https://doi.org/10.1186/s12940-018-0373-2

15. Sunyer, J.J.E.R.J. (2001). Urban air pollution and chronic obstructive pulmonary disease: a review. European Respiratory Journal, 17(5), 1024-1033. https://erj.ersjournals.com/content/17/5/1024

16. Hulin, M., Simoni, M., Viegi, G. and Annesi-Maesano, I. (2012). Respiratory health and indoor air pollutants based on quantitative exposure assessments. DOI: $10.1183 / 09031936.00159011$

17. Kumar, R., Nagar, J.K. and Gaur, S.N. (2005). Indoor air pollutants and respiratory morbidity-a review. Indian J Allergy Asthma Immunol, 19(1), 1-9. http://medind.nic.in/iac/t05/i1/iact05i1p1g.pdf

18. Maji, K.J., Dikshit, A.K. and Deshpande, A. (2017). Assessment of city level human health impact and corresponding monetary cost burden due to air pollution in India taking Agra as a model city. Aerosol Air Qual Res, 17(3), 831-842. DOI: doi: 10.4209/aaqr.2016.02.0067

19. Liu, S., Zhou, Y., Liu, S., Chen, X., Zou, W., Zhao, D., Li, X., Pu, J., Huang, L., Chen, J. and Li, B. (2017). Association between exposure to ambient particulate matter and chronic obstructive pulmonary disease: results from a cross-sectional study in China.Thorax,72(9), pp.788-795. DOI: doi: 10.1136/thoraxjnl-2016-208910. Epub 2016 Dec 9.

20. Karn, S.K., Shikura, S. and Harada, H. (2003). Living environment and health of urban poor: A study in Mumbai. Economic and Political Weekly, 3575-3586. https://www.epw.in/journal/2003/34/specialarticles/living-environment-and-health-urban-poor.html

21. Nagamine, M., Harada, N., Shigemura, J., Dobashi, K., Yoshiga, M., Esaki, N., Tanaka, M., Tanichi, M., Yoshino, A. and Shimizu, K. (2016). The effects of living environment on disaster workers: a one-year longitudinal study. BMC psychiatry, 16(1), p. 358. DOI: https://doi.org/10.1186/s12888-016-1058-4

22. Haque, M. and Singh, R.B. (2017). Air pollution and human health in Kolkata, India: A case study. Climate, 5(4), p. 77. DOI: https://doi.org/10.3390/cli5040077

23. Pandey, M.R. (1983). Domestic smoke pollution and respiratory diseases in Nepal. In Workshop Seminar on Environmental Management, July (pp. 11-12). https://pdfs.semanticscholar.org/c527/4d06b87b587d8112bb9f0cc7c2147fd8eed0.pdf 
24. Mendes, A., Papoila, A.L., Carreiro-Martins, P., Bonassi, S., Caires, I., Palmeiro, T., Aguiar, L., Pereira, C., Neves, P., Mendes, D. and Botelho, M.A.S. (2015). The impact of indoor air quality and contaminants on respiratory health of older people living in long-term care residences in Porto. Age and ageing, 45(1), 136-142. DOI: $10.1093 /$ ageing/afv 157

25. Brunekreef, B. and Holgate, S.T. (2002). Air pollution and health. The lancet, 360(9341), 1233-1242. DOI: $\quad$ https://doi.org/10.1016/S0140-6736(02)11274-8

26. Pope III, C.A., Burnett, R.T., Thurston, G.D., Thun, M.J., Calle, E.E., Krewski, D. and Godleski, J.J. (2004). Cardiovascular mortality and long-term exposure to particulate air pollution: epidemiological evidence of general pathophysiological pathways of disease. Circulation, 109(1), 71-77. DOI: 10.1161/01.CIR.0000108927.80044.7F

27. Laumbach, R.J. and Kipen, H.M. (2012). Respiratory health effects of air pollution: update on biomass smoke and traffic pollution. Journal of allergy and clinical immunology, 129(1), 3-11. DOI: 10.1016/j.jaci.2011.11.021. 